perties indicate some basic and general effect of all these drugs on cellular or organelle membranes.

\section{REFERENCES}

Bangham, A. D. (1961). Personal communication.

- and O'Brien, J. R. (1961). Unpublished observations. Rees, K. R., and Shotlander, V. (1962). Nature (Lond.) 193 754.

Gaarder, A., Jonsen, J., Laland, S., Hellem, A., and Owren, P. A. (1961). Nature, 192, 531.

Grief, R. L. (1961). In Advances in Thyroid Research, Trans. 4th int. Goitre Conf., London, 1960, p. 515. Pergamon Press, Oxford.

Hardisty, R. M., Ingram, G. I. C., and Stacey, R. S. (1956) Experientia, 12, 424.
Hellem, A. (1960). Scand. J. clin. Lab. Invest., 12, suppl. 51.

(1962). Biological Aspects of Occlusive Vascular Disease (in the press). University Press, Cambridge.

Judah, J. D. (1961a). Biochim. biophys. Acta (Amst.), 53, 375.

(1961b). Personal communication.

- (1962). Ciba Foundation Symposium on Enzymes and Drug Action, p. 339. Churchill, London.

Karzel, K., Draper, M. H., and Friebel, H. (1961). Naunyn Schmiede-ত berg's Arch. Exp. Path. Pharmak., 241, 172.

O'Brien, J. R. (1961). J. clin. Path., 14, 140.

Øllgaard, E. (1961). Thrombos. Diathes. haemorrh. (Stuttg.), 6, 86.

Sano, I., Kakimoto, Y., and Taniguchi, K. (1958). Amer. J. Physiol., $195,495$.

Shanes, A. M. (1958). Pharmacol. Rev., 10, 59.

Sharp, A. A. (1958). Brit. J. Haemat., 4, 28.

Skou, J. C. (1954). Acta pharmacol. (Kbh.), 10, 325.

Stacey, R. S. (1961). Brit. J. Pharmacol., 16, 284.

Zucker, M. B., and Borrelli, J. (1958). J. appl. Physiol., 12, 453.

,-- (1961). Blood Platelets, p. 383. Churchill, London.

\title{
Part II Some results from a new method of study
}

SYNOPSIS The light transmitted through a suspension of platelets increases if the platelets aggregate. 음 A method derived from this observation has been used to study the kinetics of platelet aggregation. $\vec{\circ}$ Aggregation is more rapid at $37^{\circ} \mathrm{C}$., with rapid stirring, with high concentrations of adenosine $\mathbb{D}$ diphosphate, and a high platelet concentration; a decrease in any of these conditions slows the $\frac{\mathbb{\mathbb { D }}}{\overrightarrow{\mathrm{O}}}$ process.

The study of platelet aggregation, that is the adhesion of one platelet to another, has been handicapped by the methods used, which include the examination of a few platelets under the microscope or the macroscopic observation of platelet suspensions agitated in a small test tube. This paper briefly reports a new method of study and amplifies the observations made in Part $\mathbf{I}$.

\section{METHOD}

Human citrated platelet-rich plasma, $3 \mathrm{ml}$, was placed in a cuvette with a cross section of $1 \times 1.5 \mathrm{~cm}$. in a simple photoelectric colorimeter. A small stirrer with a variable speed control was so placed that the blades were just submerged in the plasma. Using a green filter, the light intensity was adjusted till the reading on the optical density scale was about $0 \cdot 40$. When stirred at 1,000 r.p.m. without additions the optical density of the suspension remained practically constant. When $20 \mu \mathrm{g}$. adenosine diphosphate in $0.1 \mathrm{ml}$. of barbitone buffered saline was introduced into the stirred plasma at room temperature the optical density decreased and was read at five-second intervals; at intervals of $0,10,20,40$, and 80 seconds after the addition, $0.1 \mathrm{ml}$. of the stirred plasma was withdrawn and placed in $1.0 \mathrm{ml}$. of formol saline. The number of individual platelets and the number of clumps of platelets containing two to 10 platelets were counted in these subsamples. Technical difficulties prevented the counting of larger particles. Few if any platelets were broken up. The plasma in the cuvette finally contained many easily visible coarse platelet clumps; if cocaine was added, the platelets separated and could then be counted and this count was similar to the initial count.

\section{RESULTS}

From Fig. 1 it will be seen that for about the firstio 50 seconds the optical density decreased apparenty linearly with time, that the free platelet count de $-\frac{\bar{O}}{\mathrm{O}}$ creased rapidly and exponentially, and that smallo aggregates containing two to 10 platelets increased for 10 to 20 seconds and then decreased again. $\stackrel{\varrho}{\Rightarrow}$ After about 30 seconds it was established visually that the bulk of the platelets were in large clumps each containing 20 to 500 platelets. The optical density decreased because the light scattering power of the comparatively few coarse particles present ato the end of the experiment is less than that of the small particles, free platelets, whose diameter approaches the wavelength of light. The analysis of why the optical density initially decreased in $\mathrm{a}^{3}$ linear fashion is complicated and was not pursued. The addition of adenosine diphosphate without stirring did not alter the optical density, so it wasc concluded that the change in optical density with stirring was a faithful mirror of platelet aggregation? from single platelets to dimers, to clumps of five and to clumps of 100 or more. Since the initial rate of fall in optical density is linear and maximal fromo zero time, i.e., from the moment the adenosines diphosphate was added, it is suggested that all the्ष platelets had very rapidly become maximally 'sticky? and that thereafter adhesion depended solely on the chance of one platelet colliding with another or one clump with another. It was now possible with this 


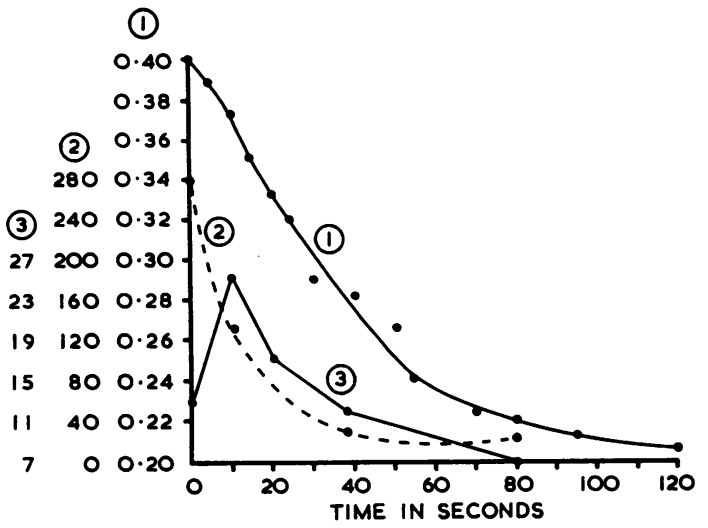

FIG. 1. Citrated plasma with 340,000 platelets per c.mm. was stirred optimally at $20^{\circ} \mathrm{C}$., at zero time sufficient adenosine diphosphate was added to give a final concentration of $6.6 \mu \mathrm{g} . / \mathrm{ml}$. Curve 1 is the optical density plotted against time; curve 2, the number of single platelets per c.mm. plotted against time; curve 3 , the number of thousands of clumps each containing two to 10 platelets plotted against time.

method to study the effect of the rate of stirring, of the number of platelets, of temperature, and of the various inhibitors, and to compare the aggregating effect of thrombin with adenosine diphosphate.

In the experiments summarized in Fig. 2 an optimal concentration of adenosine diphosphate was added to citrated platelet-rich plasma at room temperature and the speed of the stirrer was varied. At 120 r.p.m. no aggregation had occurred. At 220 r.p.m. after a short initial lag period the optical density fell linearly. Increasing the speed abolished

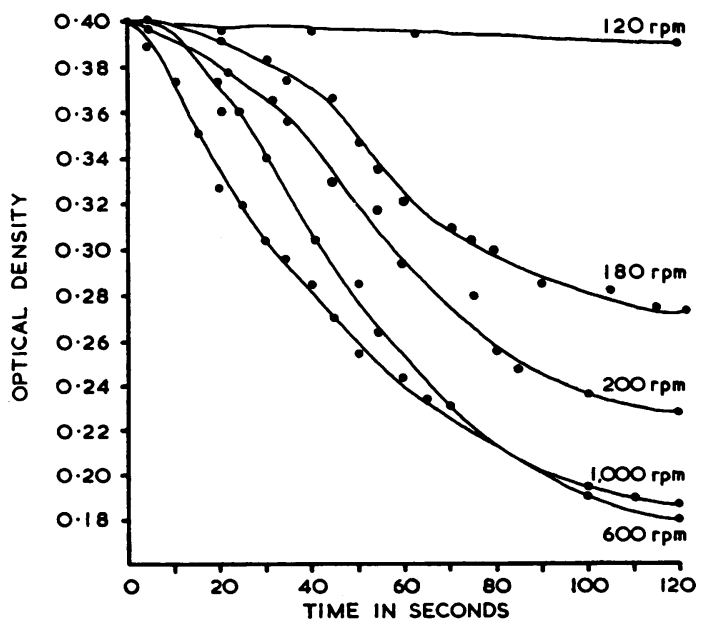

FIG. 2. The effect of different rates of stirring upon the rates of aggregation. this initial lag but did not significantly increase the maximal rate of fall in optical density. It is concluded that a certain minimum speed of collision between two platelets must be exceeded before adhesion can occur and that collisions due to Brownian movement result in negligible aggregation. The number of successful collisions should also depend on the number of platelets present in the plasma, and in fact it was found that aggregation occurred more slowly in plasma with few platelets.

The effect of varying the concentration of adenosine diphosphate was studied at three temperatures, namely $37^{\circ} \mathrm{C}$., room temperature (about $20^{\circ} \mathrm{C}$.), and at $10^{\circ} \mathrm{C}$. Figure 3 was drawn from some typical results at $37^{\circ} \mathrm{C}$. and $10^{\circ} \mathrm{C}$. The initial speed of aggregation indicated by the initial slope of the curve of optical density was less for smaller quantities of adenosine diphosphate at all three temperatures; and at each concentration of adenosine diphosphate the speed of aggregation was slower at $10^{\circ} \mathrm{C}$. than at $20^{\circ} \mathrm{C}$., which was similar to that at $37^{\circ} \mathrm{C}$. It has already been reported that at $0^{\circ} \mathrm{C}$. adenosine diphosphate produces no aggregation (O'Brien, 1962). The speed of aggregation is therefore most rapid at high temperatures and with high concentrations of adenosine diphosphate but aggregation still occurred, although slowly, at $10^{\circ} \mathrm{C}$. At $37^{\circ} \mathrm{C}$., and to a lesser extent at $20^{\circ} \mathrm{C}$., with small quantities of adenosine diphosphate the optical density after the initial almost linear fall rises again, indicating that the platelet clumps are coming apart. (With larger quantities of adenosine diphosphate the rate of aggregation decreased at roughly the same time.) If more adenosine diphosphate was added to this platelet-rich plasma that in which the aggregates had been broken up, aggregation was renewed. These observations strongly suggest that the adenosine diphosphate initially present causes aggregation and that the subsequent breaking up of aggregates is due to the inactivation or removal of adenosine diphosphate from the plasma as suggested in Part I and by Øllgaard (1961). At $10^{\circ} \mathrm{C}$. the addition of adenosine diphosphate causes a linear fall in the optical density with no subsequent rise. This fact indicates that at this temperature adenosine diphosphate causes aggregation but the diphosphate is not inactivated.

The ability of platelets to inactivate adenosine diphosphate could also be studied by incubating a standard quantity with platelet-rich plasma in the cuvette for varying times and then starting the stirrer at optimal speed; the speed of the decrease in optical density will then indicate the concentration of adenosine diphosphate in the plasma at that time. The experiments reported in Fig. 4 show that most adenosine diphosphate is 'inactivated' in the first 


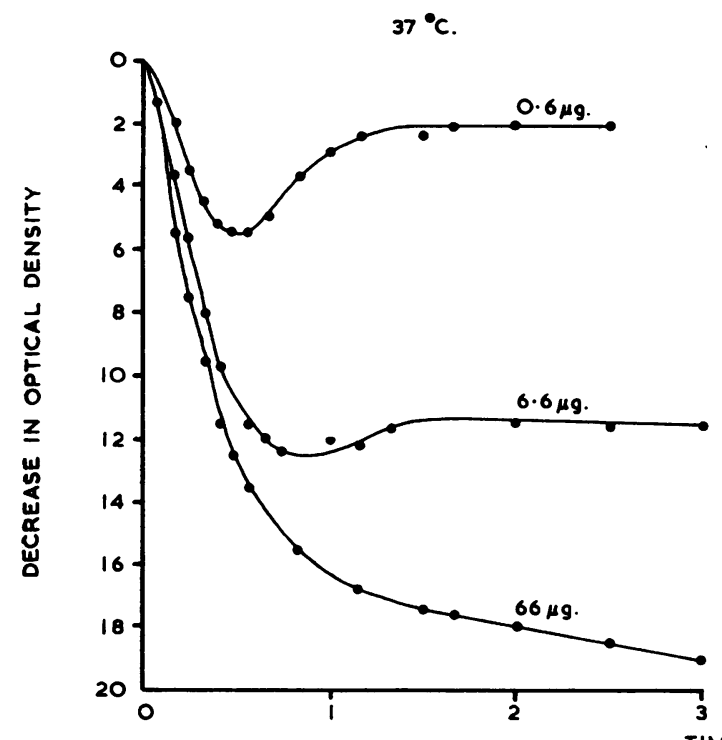

TIME IN MINUTES

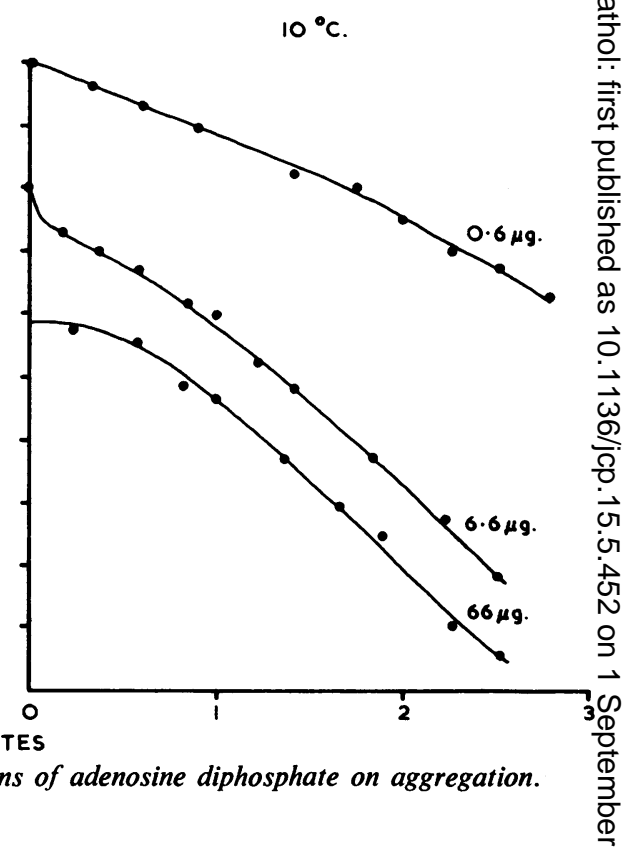

three minutes and that the rate of inactivation decreases thereafter. Adenosine diphosphate incubated with platelet-poor -plasma retained its full aggregating power and thus its inactivation by platelets is comparatively slow, occuring in minutes rather than in seconds. It is dependent on temperature and does not occur at $10^{\circ} \mathrm{C}$, and the inactivation rate is probably also dependent on the concentration of adenosine diphosphate at any given time. Since

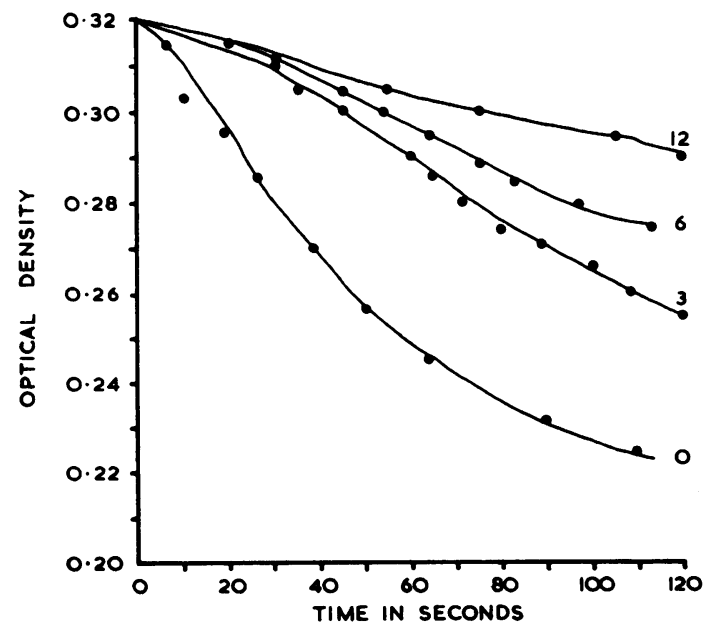

FIG. 4. Graphs showing the inactivation of adenosine diphosphate by platelet-rich plasma at $20^{\circ}$ C. after $0,3,6$, and 12 minutes' incubation. A slow fall indicates slow aggregation and less available diphosphate. inactivation occurs whether the platelets sticks together or not, i.e., in the absence of stirring ${ }^{\circ}$ i⿱⿴囗十心 can be deduced that adenosine diphosphate is tot consumed in the process of platelet adhesion. The ability of adenosine diphosphate to make platelets sticky seems to be independent of the ability o $\bar{g}$ platelets to inactivate it.

The effect of adenosine triphosphate on platele尺 aggregation was studied at $37^{\circ} \mathrm{C}$. (Fig. 5). Adeno $\overrightarrow{\vec{B}}$ sine triphosphate was added to stirred plasma an $\bar{\phi}$ when a steady state of optical density had been reached, then increasing quantities of adenosine. diphosphate were added successively and observaction of the optical density continued. It will be seero that adenosine triphosphate, which was $99 \%$ pure caused an initial aggregation and partial breaking up of aggregation ( a phenomenon that needs furthes clarification) and that thereafter the addition of small concentrations of adenosine diphosphate did not produce aggregation. With higher concentrations of adenosine triphosphate the aggregating effect of more of the diphosphate was inhibited but larges doses still produced some effect. These findings are compatible with a stoichiometric or competitive interaction between the di- and triphosphates as suggested previously in Part I. Adenosine mono? phosphate produced no initial aggregation; aparf from this the results were the same as with adenosine triphosphate.

The speed of the inhibitory action of cocaine could also be studied. Adenosine diphosphate waફ. added to stirred platelet-rich plasma at $20^{\circ} \mathrm{C}$; $2 \mathbb{P}^{\circ}$ 


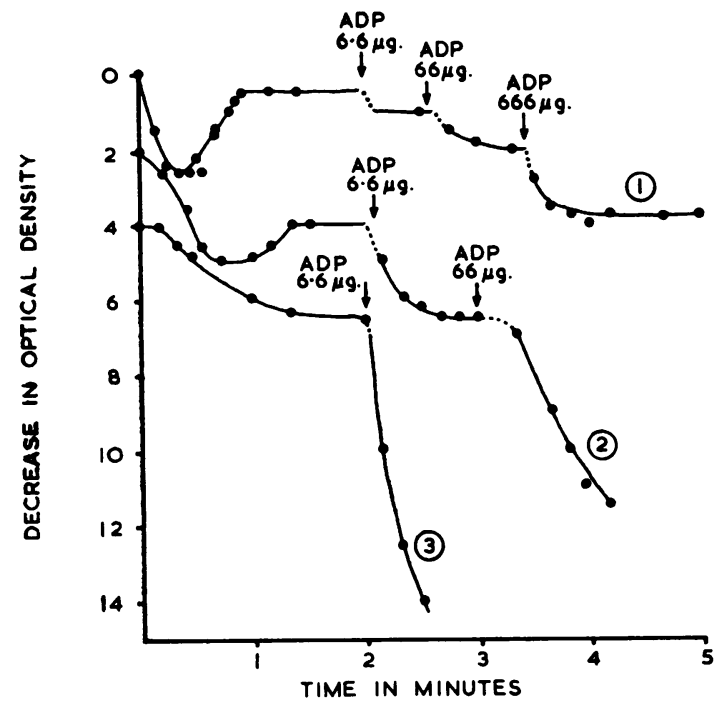

FIG. 5. Graphs showing the inhibitory effect of adenosine triphosphate on the aggregation produced by adenosine diphosphate. In experiment (1) $666 \mu \mathrm{g}$. adenosine triphosphate was added at zero time, in experiment (2) $66 \mu \mathrm{g}$., and in experiment (3) $6 \mu \mathrm{g}$.

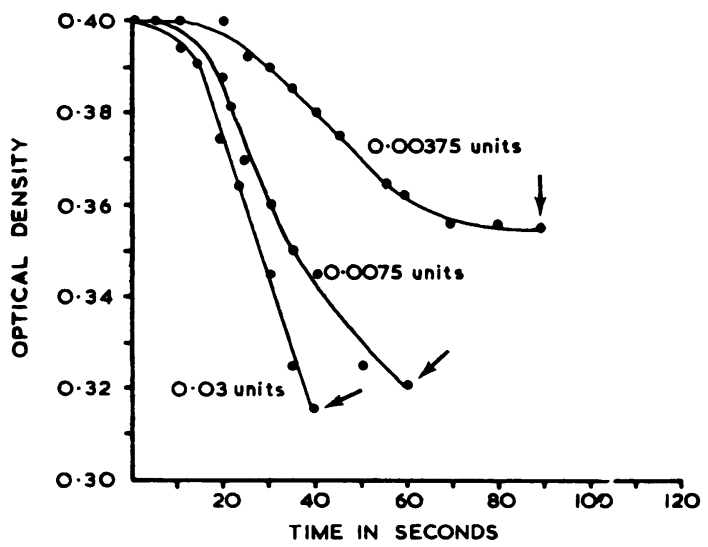

FIG. 6. Graphs showing platelet aggregation induced by thrombin. The change in optical density is plotted against time. The arrows indicate the beginning of clotting. seconds later when aggregation was occurring rapidly sufficient cocaine to give a final concentration of $3 \mathrm{mg}$. $/ \mathrm{ml}$. plasma was added. Thorough mixing was achieved in less than three seconds and by 10 seconds after the addition of cocaine there was no further decrease in optical density, indicating that aggregation had stopped completely. Thereafter the optical density increased, indicating that the aggregates were coming apart. Cocaine therefore takes less than 10 seconds to alter completely the surface of a 'sticky' platelet.

Figure 6 records the effect of adding thrombin in varying concentrations to citrated platelet-rich plasma at $20^{\circ} \mathrm{C}$. at the optimal rate of stirring. It will be seen that the higher the concentration the more rapid was the aggregation, but there was always a marked initial lag before each maximal aggregation rate was reached. This lag may be explained if thrombin acts on some mechanism that then induces stickiness through an intrinsic adenosine diphosphate system as suggested in part $I$.

Even though the exact relationship has not been worked out between platelet aggregation and the decrease in light scatter which causes a decrease in optical density, these preliminary results are reported, as clearly this method allows a detailed study of the kinetics of many of the phenomena of platelet aggregation.

\section{ADDENDUM}

Since this paper was prepared Born (1962) has reported using an absorptiometer to study platelet aggregation, and he has found that platelets aggregate and then the aggregates break up when a small quantity of adenosine diphosphate is added to citrated platelet-rich plasma, and that the monoand triphosphates inhibit aggregation induced by adenosine diphosphate.

My thanks are due to Miss J. Patrick B.Sc., for technical assistance and to the Wessex Regional Hospital Board for a research grant. My grateful thanks are also due to Dr. R. G. Macfarlane, F.R.S., for helpful advice during this work and in the preparation of this report. Dr. J. Marks of Roche Products, Dr. R. L. Greif, and Ciba Laboratories Limited supplied drugs which are gratefully acknowledged.

\section{REFERENCES}

Born, G. V. R. (1962). Nature, 194, 927.

O'Brien, 1962, as in Part 1.

Øligaard, E. (1961). Thrombos. Diathes. haemorrh. (Stuttg.), 6, 86. 